\title{
Dampak Zakat terhadap Kemiskinan dan Kesejahteraan Mustahik (Kasus : BAZNAS Provinsi Jawa Tengah)
}

\section{Impact of Zakat on Proverty and Welfare of Mustahik (Case : BAZNAS Central Java Province)}

\author{
Isro'iyatul Mubarokah¹, Irfan Syauqi Beik ${ }^{2}$, Tony $\operatorname{Irawan}^{3}$ \\ ${ }^{1}$ Mahasiswa Progam Studi Ilmu Ekonomi IPB, E-mail: isroiyatul@gmail.com \\ ${ }^{2}$ Direktur Pusat Kajian Strategis BAZNAS, E-mail: qbeiktop@gmail.com \\ ${ }^{3}$ Dosen Ilmu Ekonomi Institut Pertanian Bogor, E-mail: tonyirawan82@gmail.com
}

\begin{abstract}
Poverty is one of Indonesia's problems. One of the instruments used to reduce poverty is zakat. This study aims to analyze the impact of zakat on poverty and welfare of mustahik. The method used in this research is the interview with the questionnaire. The method of the sampling used purposive. The analysis tool used CIBEST model. The results show that the index value of Islamic poverty without and with zakat has not changed.
\end{abstract}

Keywords: CIBEST model, Islamic poverty index, poverty, welfare

\begin{abstract}
Abstrak. Kemiskinan merupakan salah satu masalah bangsa Indonesia. Salah satu instrumen yang digunakan untuk mengurangi kemiskinan adalah zakat. Penelitian ini bertujuan untuk menganalisis dampak zakat terhadap kemiskinan dan kesejahteraan mustahik. Metode yang digunakan dalam penelitian ini adalah wawancara dengan kuesioner. Pengmabilan sampel menggunakan metode purposive sampling. Alat analisis yang digunakan adalah model CIBEST. Hasil menunjukkan bahwa nilai indeks kemiskinan islami tanpa dan dengan zakat tidak mengalami perubahan.
\end{abstract}

Kata kunci: indeks kemiskinan islami, kemiskinan, kesejahteraan, model CIBEST

\section{Pendahuluan}

Salah satu masalah bangsa Indonesia adalah kemiskinan. Data kemiskinan yang tercatat di Badan Pusat Statistik (BPS) pada tahun 2016 menunjukkan bahwa jumlah penduduk miskin di Indonesia mengalami penurunan dibandingkan dengan tahun 2015. Penduduk miskin pada tahun 2015 berjumlah 28513.6 juta jiwa, sementara pada tahun 2016 mengalami penurunan menjadi 27764.32 juta jiwa (BPS 2016).

Pada tahun 2014 jumlah kemiskinan sebanyak 27727.8 juta jiwa dan meningkat pada tahun 2015 menjadi 28513.6 juta jiwa (BPS 2016). Hal tersebut disebabkan oleh inflasi akibat naiknya harga bebrabagi komoditas seperti beras, cabai rawit, dan gula pasir. Selain itu juga upah rata-rata buruh tani per hari pada Maret 2015 mengalami penurunan sebesar 1.34 persen.

Berdasarkan data kemiskinan pada gambar 1, jumlah kemiskinan di Indonesia masih sangat tinggi dan mengalami kenaikan dan penurunan. Jumlah kemiskinan pada tahun 2012 sebanyak 28590.2 jiwa dan mengalami penurunan pada tahun 2013 menjadi 28553.9. Pada tahun 2014 juga terjadi penurunan jumlah penduduk miskin menjadi 27727.8 jiwa, namun pada tahun 2015 mengalami peningkatan. Oleh karena itu perlu adanya instrument untuk mengurangi jumlah kemiskinan tersebut. salah satu instrument yang dipercaya dapat mengurangi kemiskinan adalah zakat. Dalam Al Quran pengentasan kemiskinan melalui zakat tersirat pada kalimat "memberi makan dan mengajak memberi makan orang-orang miskin" atau pada kalimat "mengeluarkan sebagian rezeki yang diberikan Allah," 
"memberikan hak orang-orang yang meminta-minta, miskin, dan terlantar dalam perjalanan", "membayar zakat" dan kalimat-kalimat lainnya (Qardawi 2011).Zakat sebagai salah satu instrumen dalam pengetasan kemiskinan akan lebih efektif jika pengelolaanya dikelola oleh suatu lembaga. Salah satunya adalah BAZNAS Provinsi Jawa Tengah.

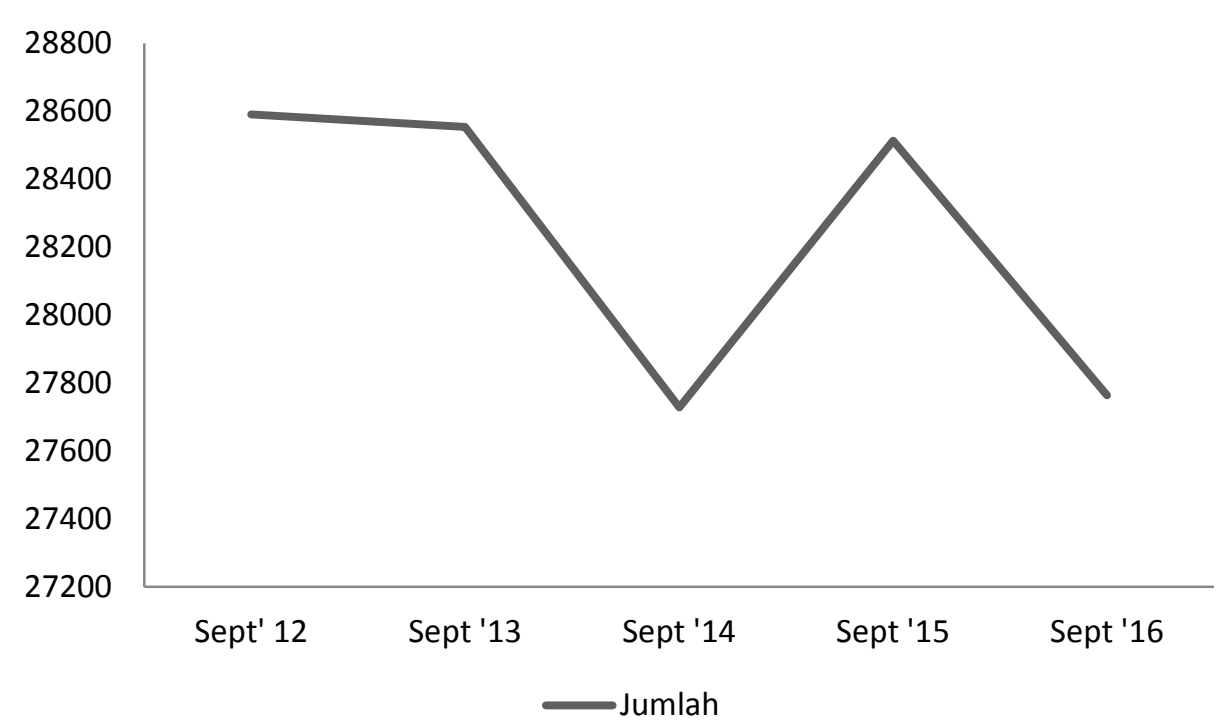

\section{Gambar 1 Jumlah Penduduk Miskin Indonesia}

Penggunaan zakat sebagai instrumen yang dapat megurangi kemiskinan selama ini masih terbatas pada pengukuran aspek material saja. Oleh Karena itu dibutuhkan suatu model yang dapat digunakan untuk mengukur aspek-aspek lainnya seperti aspek spiritual. Salah satu model yang dapat digunakan adalah CIBEST Model. CIBEST Model adalah metode pengukuran kemiskinan beradasarkan perspektif Islam dengan cara menyeimbangkan aspek material dan aspek spriritual.

Berdasarkan penjelasan tersebut, maka rumusan masalah dalam penelitian ini adalah sebagai berikut :

1. Bagaimana perubahan pendapatan rumah tangga mustahik tanpa dan dengan adanya bantuan zakat?

2. Bagaimana perubahan spiritual mustahik tanpa dan dengan adanya bantuan zakat?

3. Bagaimana klasifikasi rumah tangga mustahik berdasarkan Model CIBEST?

4. Bagaimana perubahan keadaan rumah tangga mustahik tanpa dan dengan zakat berdasarkan Model CIBEST?

Penelitian ini dilakukan dengan tujuan menganalisis dampak zakat terhadap pendapatan rumah tangga mustahik, spiritual mustahik, kuadran model CIBEST, dan keadaan rumah tangga mustahik. Instrument yang digunakan adalah uji t-statistik berpasangan dan model CIBEST yang dikembangkan oleh Beik dan Arsyanti (2015).

\section{Tinjauan Pustaka}

\subsection{Kemiskinan}

Menurut Chambers, kemiskinan dipahami sebagai keadaan kekurangan uang dan barang untuk menjamin kelangsungan hidup. Dalam arti luas, mengatakan bahwa kemiskinan adalah suatu intergrated concept yang memiliki lima dimensi, yaitu: kemiskinan (proper), 
ketidakberdayaan (powerless), kerentanan menghadapi situasi darurat (state of emergency), ketergantungan (dependence), dan keterasingan (isolation) baik secara geografis maupun sosiologis (Prastyo 2010). Kemiskinan dikelompokkan menjadi lima jenis (Mardimin 1996), yaitu kemiskinan absolut, kemiskinan relative, kemiskinan structural, kemiskunan situasional atau natural, dan kemiskinan kultural.

Dalam Islam, kemiskinan dan kesenjangan dipandang sebagai sunatullah dan tidak bisa dihilangkan. Islam tidak pernah berbicara bagaimana menghilangkan kemiskinan, tetapi Islam berbicara mengenai bagaimana meminimalisir kemiskinan dan mencapai kesejahteraan. Salah satu instrumen yang dapat meminimalisir kemiskinan adalah dengan zakat (Hafidudin 2008).

Dalam Islam kemiskinan memiliki sifat multidimensional. Maksudnya adalah kemiskinan tidak hanya dipandang dari aspek material semata melainkan juga melihat aspek spiritual. Konsep kemiskinan yang demikian dilandaskan pada dalil Al-Qur'an seperti yang terdapat dalam Surat Thoha ayat 118-120 dan Surat Al Quraisy ayat 3-4 yang menyatakan bahwa kebutuhan pokok yang harus dipenuhi oleh umat muslim adalah dapat melaksanakan ibadah dengan baik, tercukupinya kebutuhan sandang, pangan, dan papan, serta hilangnya rasa takut atau tidak adanya ancaman dan tekanan dari berbagai pihak (Beik \& Arsyianti 2015).

\subsection{Zakat}

Menurut Hafidhuddin (2008) secara bahasa, zakat artinya tumbuh dan berkembang. Kata zakat memiliki sejumlah arti, yaitu al-barakatu yang artinya keberkahan, an-namaa yang artinya tumbuh dan berkembang, at-thaharatu yang artinya kesucian, serta ash-shalahu yang artinya keberesan. Secara istilah, zakat didefinisikan sebagai harta dengan persyaratan tertentu, yang Allah SWT wajibkan kepada pemiliknya (muzakki) untuk diserahkan kepada yang berhak menerimanya (mustahik) dengan persyaratan tertentu (Beik 2009).

Adapun golongan yang berhak menerima zakat telah diatur dalam ajaran syariat Islam, yakni ada delapan golongan yaitu fakir, miskin, amil, muallaf, riqab (para budak), gharimin, fi sabilillah ( orang yang berjuang di jalan Alloh), dan ibnu sabil (orang yang dalam perjalanan). Ketentuan ini diatur dalam Al Qur'an surat At-Taubah ayat 60 yang artinya

"Sesungguhnya shadaqah (zakat) itu hanyalah untuk orangorang fakir, orangorang miskin, penguus-pengurus zakat, para mualaf yang di bujuk hatinya, untuk (memerdekakan) budak, orang-orang yang berhutang, untuk jalan Allah, dan orangorang yang sedang dalam perjalanan, sebagai suatu ketetapan yang diwajibkan Allah dan Allah Maha mengetahui lagi Maha Bijaksana". (Q.S. At-Taubah: 60)

Manfaat dan hikmah zakat diantaranya yaitu tumbuh dan berkembang, zakat pemacu ibadah, zakat dan etos kerja, zakat dan etika bekerja, zakat dan pembangunan umat, zakat dan ketenangan, zakat mengatasi krisis kemanusiaan, dan zakat menolak musibah (Hafidudin 2008).

\subsection{Penelitian Terdahulu}

Penelitian mengenai dampak zakat terhadap pengurangan kemiskinan pernah dilakukan oleh Beik (2009) dengan studi kasus Dompet Dhuafa Republika. Hasil dari penelitian tersebut menunjukkan bahwa setelah adanya pendistribusian dana zakat kemiskinan berkurang sebesar 10 persen dari 84 persen menjadi menjadi 74 persen. 
Beik dan Arsyianti (2015) membentuk model CIBEST dan melakukan penelitian dengan judul Construction of CIBEST Model as Measurement of Poverty and Welfare Indices From Islamic Perspective. Hasilnya menjelaskan bahwa konsep kemiskinan dan kesejahteraan dalam perspektif Islam tidak hanya dilihat dari dimensi material, tetapi juga dilihat dari dimensi spiritual. Penelitian ini berhasil memformulasikan model CIBEST yang terdiri dari indeks kesejahteraan, indeks kemiskinan material, indeks kemiskinan spiritual, dan indeks kemiskinan absolut. Indeks ini didasarkan pada konsep kuadran CIBEST yang mewakili konsep Islam tentang kemiskinan dan kesejahteraan.

Pada tahun 2015, Pratama menganalisis dampak pendayagunaan zakat produktif dalam mengurangi kemiskinan dengan studi kasus PT Masyarakat Mandiri Dompet Dhuafa. Hasil penelitian tersebut menunjukkan rata-rata pendapatan rumah tangga mustahik mengalami peningkatan setelah adanya pendistribusian dana zakat. Qonita (2015) melakukan penelitian di BAZIS Provinsi DKI Jakarta yang menunjukan bahwa pendistribusian dana zakat yangdilakukan oleh BAZIS Provinsi DKI Jakarta terbukti dapat mengurangi tingkat kemiskinan dan kesenjangan mustahik.

Widyaningsih (2016) melakukan penelitian mengenai dampak zakat di Sulawesi Selatan dengan menggunakan model CIBEST dan menunjukkan hasil yang sama. Muslihah (2016) juga menganalisis dampak pendistribusian dana zakat yang dilakukan oleh LAZ PM Al Bunyan dalam mengurangi tingkat kemiskinan Hasil dari penelitian ini adalah pendistribusian dana zakat mampu meningkatkan kesejahteraan rumah tangga mustahik mampu menurunkan kemiskinan.

\section{Metode Penelitian}

\subsection{Jenis dan Sumber Data}

Sumber data penelitian ini terbagi menjadi 2 bagian, yaitu data primer dan data sekunder. Data primer adalah data yang didapat melalui metode survey dan wawancara langsung dengan responden penelitian. Sedangkan data sekunder adalah data yang diperoleh melalui survey literatur, seperti jurnal, buku, laporan tahunan BAZNAS Provinsi Jawa Tengah dan lain sebagainya.

\subsection{Waktu dan Lokasi Penelitian}

Penelitian ini dilakukan pada bulan Maret 2017, dengan mengambil lokasi di wilayah Kota Semarang. Dipilihnya Kota Semarang sebagai lokasi penelitian karena daerah ini merupakan perseberan mustahik terbanyak yang menerima bantuan dana zakat dari BAZNAS Provinsi Jawa Tengah.

\subsection{Populasi dan Metode Pengambilan Sampel}

Responden yang menjadi sampel dalam penelitian ini berjumlah 100 orang yang merupakan mustahik yang menerima penyaluran zakat dari BAZNAS Provinsi Jawa Tengah bidang ekonomi pada tahun 2016. Jumlah populasi dalam penelitian ini adalah sebanyak 1.080 mustahik. Karena keterbatasan kelengkapan data, sampel yang menjadi responden dalam penelitian ini adalah orang yang terdata lengkap oleh BAZNAS Provinsi Jawa Tengah dan yang mudah untuk ditemukan. Oleh karena itu, metode yang digunakan dalam pengambilan sampel adalah metode convenience sampling. Penentuan jumlah mustahik yang menjadi sampel adalah menggunakan rumus slovin sebagai berikut: 
$n=\frac{N}{1+N e^{2}}=\frac{1080}{1+1080 \times 0,1^{2}}=97,5$

dimana

$n$ : jumlah sampel

$\mathrm{N}$ : jumlah populasi

e: batas toleransi kesalahan (error tolerance)

Jumlah mustahik bidang ekonomi BAZNAS Provinsi Jawa Tengah pada tahun 2016 adalah sebanyak 1.080 mustahik. Batas toleransi kesalahan yang digunakan peneliti adalah $10 \%$. Berdasarkan perhitungan dengan rumus slovin mendapatkan jumlah sampel 97,5 yang kemudian oleh peneliti dibulatkan menjadi 100 sampel.

\subsection{Metode Analisis}

Indeks kemiskinan yang digunakan dalam menentukan kondisi rumah tangga mustahik adalah indeks kemiskinan Islami Center of Islamic Business and Economics Studies (CIBEST) Institut Pertanian Bogor (IPB) yang dikembangkan oleh Beik dan Arsyianti (2015).

Perhitungan yang digunakan sebagai dasar perhitungan dalam penelitian ini adalah nilai Material Value (MV) atau garis kemiskinan rumah tangga dan pendapatan rumah tangga per bulan. Material Value (MV) digunakan untuk mengukur standar minimal material yang harus dipenuhi oleh rumah tangga. Nilai MV diperoleh dengan mengalikan harga barang dan jasa yang dikonsumsi (Pi) dengan jumlah minimal barang dan jasa yang dibutuhkan (Mi). Secara matematis, MV dapat dirumuskan sebagai berikut:

$$
M V=\sum_{i=1}^{n} P i M i
$$

Keterangan:

MV = Standar minimal material yang harus dipenuhi oleh rumah tangga ( $\mathrm{Rp}$ atau mata uang lain) atau bisa disebut Garis Kemiskinan Material

$\mathrm{Pi} \quad=$ Harga barang dan jasa (Rp atau mata uang lain)

Mi = Jumlah minimal barang dan jasa yang dibutuhkan

Karena adanya keterbatasan dan tidak dilakukannya survei dalam penelitian ini, maka nilai MV yang digunakan dalam penelitian ini adalah nilai MV yang sudah ada yaitu garis kemiskinan material Kota Semarng yang nantinya akan dikonversikan menjadi garis kemiskina rumah tangga per kapita per bulan. Perhitungan garis kemiskinan diperoleh dengan mengalikan garis kemiskinan per kapita per bulan dengan rata-rata besaran ukuran rumah tangga. Rata-rata besaran ukuran rumah tangga didapat dari rasio total penduduk dengan jumlah rumah tangga di wilayah yang diteliti (Tsani 2010).

Garis kemiskinan beradasarkan garis kemiskinan Kota Semarang tahun 2015 yaitu sebesar Rp 368.477 (BPS Kota Semarang 2015). Daerah menjadi tempat dilaksanakannya penelitian meliputi semua kecamatan di Kota Semarang dengan total jumlah penduduk dan rumah tangga di masing-masing wilayah berjumlah 1.595.187 orang dan 471.327 rumah tangga (BPS Kota Semarang 2015)

Rata-rata ukuran rumah tangga : $\frac{1.595 .187}{471.327}=3,384$ 
Sehingga garis kemiskinan rumah tangga (MV) yang diperoleh adalah :

$$
\begin{aligned}
\text { MV } & =\operatorname{Rp} 368.477 \times 3,384 \\
& =\operatorname{Rp} 1.246 .926 \text { per rumah tangga per bulan }
\end{aligned}
$$

Garis kemiskinan spiritual atau Spiritual Value (SV) diperoleh beradasarkan indikator kebutuhan spiritual dan pemenuhan lima variabel yang menentukan skor spiritual. Lima variabel tersebut adalah ibadah shalat, zakat, puasa, lingkungan rumah tangga, dan kebijakan pemerintah. Untuk menilai skor dari variabel-variabel tersebut digunakan skala likert 1-5 seperti pada Tabel 1.

\begin{tabular}{|c|c|c|c|c|c|c|}
\hline \multirow{2}{*}{$\begin{array}{c}\text { Variabe } \\
1\end{array}$} & \multicolumn{5}{|c|}{ Skala Likert } & \multirow{2}{*}{$\begin{array}{c}\text { Srandar } \\
\text { Kemiskina } \\
\mathrm{n}\end{array}$} \\
\hline & 1 & 2 & 3 & 4 & 5 & \\
\hline Shalat & $\begin{array}{l}\text { Melarang } \\
\text { orang lain } \\
\text { shalat }\end{array}$ & $\begin{array}{l}\text { Menolak } \\
\text { konsep } \\
\text { shalat }\end{array}$ & $\begin{array}{l}\text { Melaksana- } \\
\text { kan shalat } \\
\text { wajib tidak } \\
\text { rutin }\end{array}$ & $\begin{array}{l}\text { Melaksana- } \\
\text { kan shalat } \\
\text { wajib rutin } \\
\text { tapi tidak } \\
\text { selalu } \\
\text { berjamaah }\end{array}$ & $\begin{array}{l}\text { Melaksana- } \\
\text { kan shalat } \\
\text { wajib rutin } \\
\text { berjamaah } \\
\text { dan } \\
\text { melaksana- } \\
\text { kan solat } \\
\text { Sunnah }\end{array}$ & \\
\hline Puasa & $\begin{array}{l}\text { Melarang } \\
\text { orang lain } \\
\text { berpuasa }\end{array}$ & $\begin{array}{l}\text { Menolak } \\
\text { konsep } \\
\text { puasa }\end{array}$ & $\begin{array}{l}\text { Melaksana- } \\
\text { kan puasa } \\
\text { wajib tidak } \\
\text { penuh }\end{array}$ & $\begin{array}{l}\text { Hanya } \\
\text { melaksana- } \\
\text { kan puasa } \\
\text { wajib secara } \\
\text { penuh }\end{array}$ & $\begin{array}{l}\text { Melaksana- } \\
\text { kan puasa } \\
\text { wajib dan } \\
\text { puasa Sunnah }\end{array}$ & $\begin{array}{l}\text { Skor rata- } \\
\text { rata untuk } \\
\text { keluarga } \\
\text { yang } \\
\text { secara } \\
\text { spiritual }\end{array}$ \\
\hline $\begin{array}{l}\text { Zakat } \\
\text { dan } \\
\text { Infak }\end{array}$ & $\begin{array}{l}\text { Melarang } \\
\text { orang lain } \\
\text { berzakat } \\
\text { dan infak }\end{array}$ & $\begin{array}{l}\text { Menolak } \\
\text { zakat dan } \\
\text { infak }\end{array}$ & $\begin{array}{l}\text { Tidak pernah } \\
\text { berinfak } \\
\text { walau sekali } \\
\text { dalam } \\
\text { setahun }\end{array}$ & $\begin{array}{l}\text { Membayar } \\
\text { zakat fitrah } \\
\text { dan zakat } \\
\text { harta }\end{array}$ & $\begin{array}{l}\text { Membayar } \\
\text { zakat fitrah, } \\
\text { zakat harta } \\
\text { dan infaq/ } \\
\text { sedekah }\end{array}$ & $\begin{array}{l}\text { miskin } \\
\text { adalah } 3 \\
(\mathrm{SV}=3)\end{array}$ \\
\hline $\begin{array}{l}\text { Lingku } \\
\text { ngan } \\
\text { Keluar } \\
\text { ga }\end{array}$ & $\begin{array}{l}\text { Melarang } \\
\text { anggota } \\
\text { keluarga } \\
\text { beribadah }\end{array}$ & $\begin{array}{l}\text { Menolak } \\
\text { pelaksana } \\
\text { an ibadah }\end{array}$ & $\begin{array}{l}\text { Menganggap } \\
\text { ibadah } \\
\text { urusan } \\
\text { anggota } \\
\text { keluarga }\end{array}$ & $\begin{array}{l}\text { Mendukung } \\
\text { ibadah } \\
\text { anggota } \\
\text { keluarga }\end{array}$ & $\begin{array}{l}\text { Membangun } \\
\text { suasana } \\
\text { keluarga } \\
\text { yang } \\
\text { mendukung } \\
\text { ibadah secara } \\
\text { bersama- } \\
\text { sama }\end{array}$ & \\
\hline $\begin{array}{l}\text { Kebijak } \\
\text { an } \\
\text { Pemeri } \\
\text { ntah }\end{array}$ & $\begin{array}{l}\text { Melarang } \\
\text { ibadah } \\
\text { untuk } \\
\text { anggota } \\
\text { keluarga }\end{array}$ & $\begin{array}{l}\text { Menolak } \\
\text { pelaksana } \\
\text { an ibadah }\end{array}$ & $\begin{array}{l}\text { Menganggap } \\
\text { ibadah } \\
\text { urusan } \\
\text { pribadi } \\
\text { masyarakat }\end{array}$ & $\begin{array}{l}\text { Mendukung } \\
\text { ibadah }\end{array}$ & $\begin{array}{l}\text { Menciptakan } \\
\text { lingkungan } \\
\text { yang } \\
\text { kondusif } \\
\text { untuk ibadah }\end{array}$ & \\
\hline
\end{tabular}

Tabel 1 Skor Spiritual CIBEST

Sumber : Beik dan Arsyanti 2016

Berdasarkan Tabel 1, maka diperoleh nilai SV sama dengan 3. Jika sebuah rumah tangga memiliki skor lebih kecil atau sama dengan tiga maka rumah tangga tersebut dapat dikategorikan ke dalam kategori miskin spiritual. Nilai SV diperoleh dengan cara sebagai berikut: 


$$
H i=\frac{V p+V f+V z+V h+V g}{5}
$$

$$
\begin{aligned}
& \text { Keterangan }: \\
& \mathrm{Hi}=\text { Skor aktual anggota rumah tangga ke-i } \\
& \mathrm{Vp}=\text { Skor shalat } \\
& \mathrm{Vf}=\text { Skor puasa } \\
& \mathrm{Vz}=\text { Skor zakat dan infak } \\
& \mathrm{Vh}=\text { Skor lingkungan kerja } \\
& \mathrm{Vg}=\text { Skor kebijakan pemerintah }
\end{aligned}
$$

Setelah melakukan perhitungan SV dan MV maka rumah tangga dapat dikategorikan ke dalam kuadran CIBEST sebagai berikut:

Tabel 2 Kuadran CIBEST

\begin{tabular}{llll}
\hline Skor Aktual & $\leq$ Nilai MV & $>$ Nilai MV & \\
\hline$>$ Nilai SV & $\begin{array}{l}\text { Kaya Spiritual, miskin } \\
\text { material (Kuadran II) }\end{array}$ & $\begin{array}{l}\text { Kaya Spiritual, kaya } \\
\text { material (Kuadran I) }\end{array}$ \\
$\leq$ Nilai SV & $\begin{array}{l}\text { Miskin spiritual, miskin } \\
\text { material (Kuadran IV) }\end{array}$ & $\begin{array}{l}\text { Miskin Spiritual, kaya } \\
\text { material (Kuadran III) }\end{array}$ \\
\hline
\end{tabular}

Sumber : Beik dan Arsyanti 2016

Tabel di atas dapat dijelaskan sebagai berikut:

Kuadran I : Jika nilai aktual skor spiritual rumah tangga (SH) lebih besar dari SV dan pendapatannya lebih besar dari MV.

Kuadran II $\quad$ : Jika nilai SH lebih besar dari SV dan pendapatan lebih rendah dari MV.

Kuadran III $\quad$ : Jika nilai SH lebih kecil dari SV dan pendapatan lebih besar dari MV.

Kuadran IV : Jika nilai SH lebih kecil dari SV dan pendapatan lebih kecil dari MV.

Tahap terakhir yaitu menghitung semua indeks CIBEST yang terdiriri dari indeks kesejahteraan (W), indeks kemiskinan material, indeks kemiskinan spiritual, dan indeks kemiskinan absolut.

Indeks kesejahteraan (W)

$$
W=\frac{W}{N}
$$

Keterangan :

$\mathrm{W}=$ Indeks kesejahteraan; $0 \leq \mathrm{W} \leq 1$

$\mathrm{w}=$ Jumlah keluarga sejahtera (kaya secara material dan spiritual)

$\mathrm{N}$ = Jumlah populasi (jumlah keluarga yang diobservasi)

1. Indeks kemiskinan material $(\mathrm{Pm})$ 
Keterangan:

$$
P m=\frac{M p}{N}
$$

$\mathrm{Pm}=$ Indeks kemiskinan material $; 0 \leq \mathrm{Pm} \leq 1$

$\mathrm{Mp}=$ Jumlah keluarga yang miskin secara material namun kaya secara spiritual $\mathrm{N}=$ Jumlah populasi (rumah tangga yang diamati)

2. Indeks kemiskinan spiritual (Ps)

$$
P s=\frac{S p}{N}
$$

Keterangan:

Ps $=$ Indeks kemiskinan spiritual; ; $0 \leq \mathrm{Ps} \leq 1$

Sp $=$ Jumlah keluarga yang miskin secara spiritual namun berkecukupan secara material

$\mathrm{N}=$ Jumlah populasi total rumah tangga yang diamati

3. Indeks kemiskinan absolut $(\mathrm{Pa})$

Keterangan:

$$
P a=\frac{A p}{N}
$$

$\mathrm{Pa}=$ Indeks kemiskinan absolut; ; $0 \leq \mathrm{Pa} \leq 1$

Ap = Jumlah keluarga yang miskin secara spiritual dan juga material

$\mathrm{N}=$ Jumlah populasi total rumah tangga yang diamati

\section{Hasil dan Pembahasan}

\subsection{Gambaran umum BAZNAS Provinsi Jawa Tengah}

BAZNAS Provinsi Jawa Tengah adalah sebuah lembaga pemerintah non struktural yang bersifat mandiri. Lembaga ini merupakan pengelola zakat yang bertugas melakukan pengumpulan, pendistribusian, dan pendayagunaan dana zakat tingkat provinsi. BAZNAS Provinsi Jawa Tengah bertanggung jawab kepada Gubernur melalui melalui Sekretaris Daerah dan Baznas Pusat. BAZNAS Provinsi Jawa Tengah berkedudukan di ibu kota provinsi yaitu di Kompleks Kantor Gubernur, Jl. Menteri Supeno no. 2B Semarang (Gedung Dharma wanita Lt. 4).

Sejak tahun 2015, penghimpunan yang dilakukan BAZNAS Provinsi Jawa Tengah meningkat. Pendistribusian zakat dilakukan melaalui progam kerja BAZNAS Provinsi Jawa Tengah yang terdiri dari Jateng makmur, Jateng Cerdas, Jateng Peduli, Jateng Sehat, dan Jateng taqwa.

Tabel 3 Jumlah Penghimpunan Dana Zakat

\begin{tabular}{cc}
\hline Tahun & Total Penghimpunan \\
\hline 2015 & 487.695 .380 \\
2016 & 8.612 .304 .620 \\
\hline Sumber : Laporan Keuangan BAZNAS Provinsi Jawa Tengah 2016
\end{tabular}

Berdasarkan Tabel 3 diatas, terlihat bahwa penghimpunan dana zakat BAZNAS Provinsi Jawa Tengah pada tahun 2016 mengalami peningkatan sebesar 17,7 kali lipat. Hal tersebut mengindikasikan bahwa meningkatnya kesadaran wajib zakat (muzakki) untuk membayar zakat dan peningkatan kepercayaan dari masyarakat kepada BAZNAS Provinsi Jawa Tengah untuk mengelola dana zakat. 


\subsection{Karakteristik mustahik}

Responden dalam penelitian ini berjumlah 100 orang. Responden adalah mustahik penerima bantuan dana zakat konsumtif dari BAZNAS Provinsi Jawa Tengah. Berikut adalah karakteristik responden yang menerima bantuan dari BAZNAS Provinsi Jawa Tengah :

\section{Tabel 4 Karakteristik Mustahik}

\begin{tabular}{lc}
\hline \multicolumn{1}{c}{ Karakteristik } & Jumlah \\
\hline Jenis Kelamin & \\
Laki-laki & 86 \\
Perempuan & 14 \\
Pendidikan & \\
Tidak Sekolah & 3 \\
SD & 18 \\
SMP / Sederajat & 22 \\
SMA / Sederajat & 50 \\
>SMA & 7 \\
Pekerjaan & \\
Tidak Bekerja & 8 \\
Karyawan & 40 \\
Buruh & 8 \\
Cleaning Service & 28 \\
Lain-lain & 16 \\
Ukuran Keluarga & 62 \\
1-3 orang & 38 \\
4-6 & \\
\hline Sumber : Data Primer 2017
\end{tabular}

Sumber : Data Primer 2017

Berdasarkan Tabel 4 di atas, mayoritas penerima bantuan dana zakat dari BAZNAS Provinsi Jawa Tengah adalah laki-laki, yaitu sebanyak 86 persen. Sedangkan penerima bantuan dana zakat yang berjenis kelamin perembuan berjumlah 14 orang atau 14 persen. Tingkat pendidikan mustahik yang tidak bersekolah berjumlah 3 orang. Musathik yang menempuh pendidikannya sampai dengan jenjang pendidikan sekolah dasar (SD) sebanyak 18 orang. Sedangkan yang menempuh pendidikan hingga sekolah menengah pertama (SMP/sederajat) sebanyak 22 orang. Sementara mustahik yang menempuh pendidikan hingga sekolah menengah atas (SMA / sederajat) sebanyak 50 orang. Dan sisanya sebanyak 7 orang menempuh jenjang pendidikan lebih dari SMA.

Dilihat dari pekerjaan, mustahik yang tidak bekerja sebanyak 8 orang, yangbekerja sebagai karyawan 40 orang, yang bekerja sebaga buruh 8 orang, yang bekerja sebagai cleaning service sebanyak 28 orang, dan 16 sisanya ada yang sebagai pedagang, supir, kurir, dan lainnya. Jumlah ukuran rumah tangga 62 persen sebanyak 1-3 orang dan 38 persen mempunyai jumlah keluarga sebanyak 4-6 orang.

\subsection{Analisis dampak bantuan zakat terhadap pendapatan mustahik}

Tabel 5 Rata-Rata Perubahan Pendapatan Mustahik

\begin{tabular}{lc}
\hline & Rata-Rata Pendapatan \\
\hline Tanpa Adanya Bantuan Zakat & 2.160 .530 \\
Dengan Adanya Bantuan Zakat & 2.660 .530 \\
\hline
\end{tabular}


Berdasarkan Tabel 5 di atas terlihat bahwa pendistribusian dana zakat memiliki dampak terhadap pendapatan rumah tangga mustahik. Dampak yang ditimbulkan oleh pendistribusian dan pendayagunaan zakat adalah dampak yang positif. Hal ini dapat dilihat dari adanya peningkatan rata-rata pendapatan rumah tangga mustahik tanpa dan dengan adanya bantuan dana zakat. Sebelum adanya bantuan dana zakat yang diberikan oleh BAZNAS Provinsi Jawa Tengah rata-rata pendapatan rumah tangga mustahik secara keseluran sebesar Rp 2.160.530 dan setelah mendapatkan bantuan dana zakat, rata-rata pendapatan rumah tangga mustahik secara keseluruhan naik menjadi $\mathrm{Rp} 2.660 .530$. Artinya terjadi peningkatan rata-rata pendapatan rumah tangga mustahik sebesar Rp 500.000.

Pendapatan yang diperoleh responden yang dibawah garis kemiskinan rumah tangga ( < $\mathrm{Rp}$ 1.246.926) yaitu sejumlah 14 rumah tangga. Sedangkan yang di atas garis kemiskinan rumah tangga (>Rp 1.246.926) sebanyak 86 rumah tangga. Hal ini menunjukkan bahwa sebagian besar rumah tangga yang menerima bantuan dan zakat dari BAZNAS Provinsi Jawa Tengah bukan merupakan golongan fakir miskin.

\subsection{Analisis dampak bantuan zakat terhadap spiritual mustahik}

Variabel spiritual yang digunakan adalah ibadah shalat, puasa, zakat dan infak, lingkunagn keluarga, dan kebijakan pemerintah (Beik \& Arsyanti 2015). Setiap mustahik dinilai masing-masing variabel kemudian dirata-rata. Nilai rata-rata yang diperoleh kemudian diolah menggunakan uji t-statistik berpasangan.

Hasil dari pengolahan data skor spiritual mustahik dengan uji t-statistik berpasangan didapatkan hasil signifikansi sebesar 0.000. Nilai signifikansi lebih kecil dari taraf nyata lima persen. Artinya terdapat perbedaan skor spiritual mustahik tanpa dan dengan adanya bantuan zakat.

\subsection{Analisis kuadran cibest tanpa dan dengan adanya bantuan zakat dari baznas provinsi jawa tengah}

Model CIBEST terdiri dari kuadran CIBEST dan indeks CIBEST. Kuadran CIBEST adalah sebuah kuadran yang bertujuan untuk memetakan keluarga dalam empat area, yaitu area kesejahteraan (kuadran I), area kemiskinan material (kuadran II), area kemiskinan spiritual (kuadran III), dan area kemiskinan absolut (kuadran IV). Sedangkan indeks CIBEST digunakan untuk melihat nilai indeks pada masing-masing kuadran CIBEST (Beik dan Arsyianti 2015). 


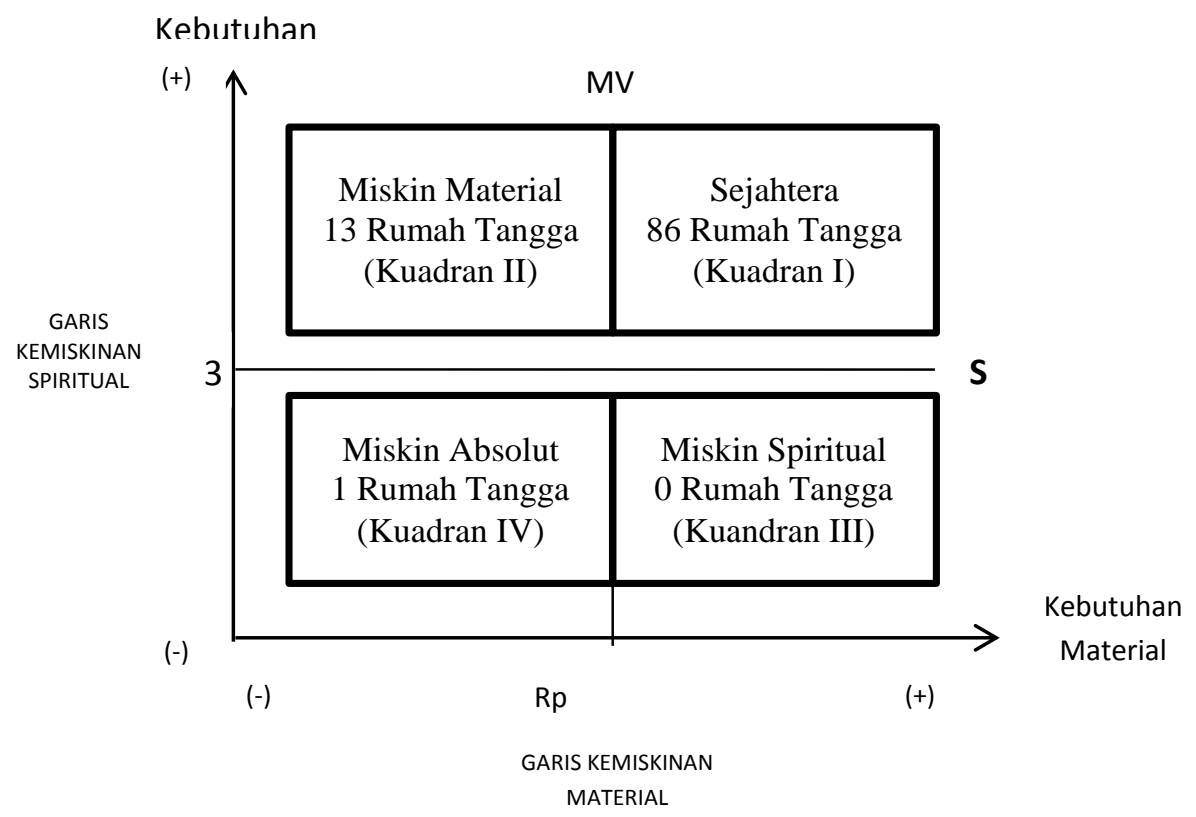

\section{Gambar 2 Kuadran CIBEST Tanpa Adanya Bantuan Zakat}

Berdasarkan analisis kuadran CIBEST tanpa adanya bantuan zakat seperti ditunjukkan pada Gambar 2, jumlah keluarga yang berada di kuadran I atau yang kaya secara material dan spiritual ada sebanyak 86 rumah tangga. Sedangkan di kuadran II jumlah keluarga yang miskin secara material namun kaya spiritual sebanyak 13 rumah tangga. Sementara keluarga yang masuk kategori kuadran III atau miskin spiritual tidak ada. Dan yang masuk kategori kuadran IV atau miskin secara material dan spiritual hanya terdapat 1 rumah tangga.

Dengan adanya bantuan zakat, kesejahteraan rumah tangga mustahik meningkat seperti terlihat pada Gambar 3. Jumlah rumah tangga sejahtera (Kuadran I) meningkat menjadi 94 rumah tangga. Rumah tangga dengan kategori miskin material (Kuadran II) menurun menjadi 5 rumah tangga. Dan rumah tangga dengan kategori miskin spiritual(Kuadran III) dan miskin absolut tidak berubah yaitu 0 rumah tangga dan 1 rumah tangga.

Hasil penelitian ini sama dengan hasil penelitian sebelumnya yang dilakukan oleh Pratama (2015), Widyaningsih (2016), dan Muslihah (2016) yang menghasilkan analisis kuadran CIBEST sebelum dan sesudah adanya bantuan zakat mengalami perubahan. 


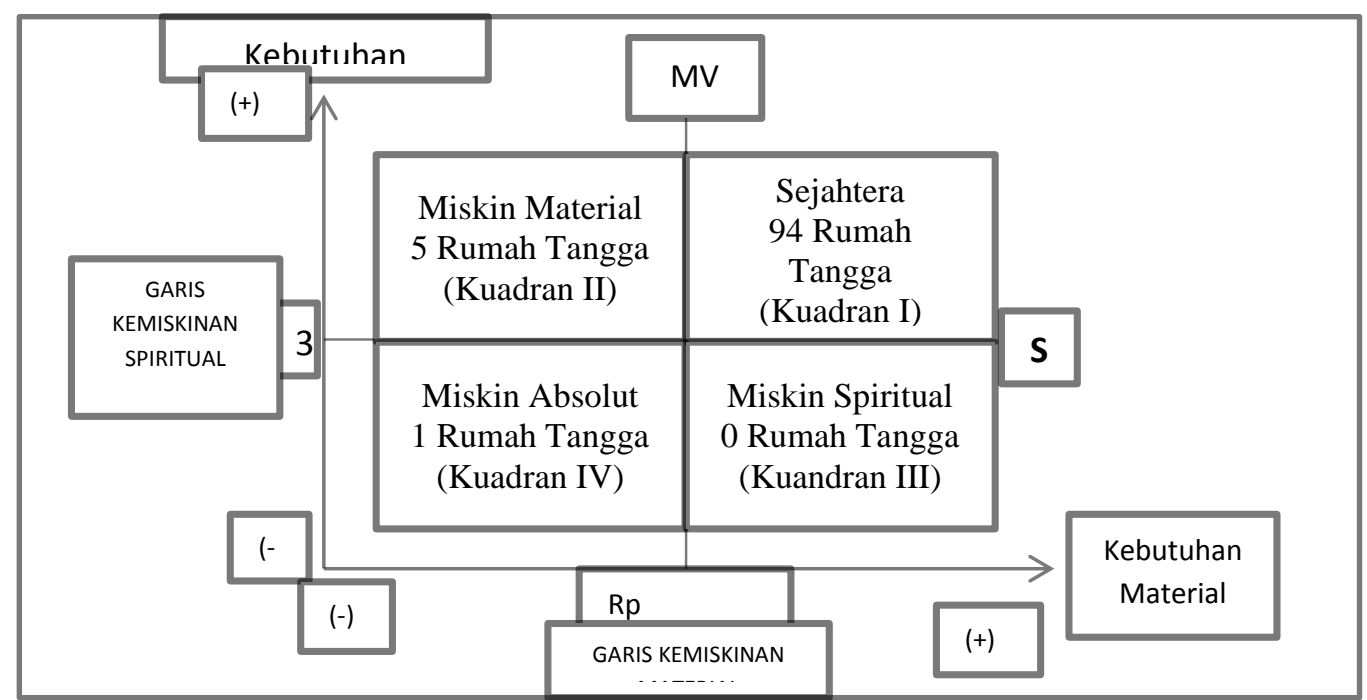

\section{Gambar 3 Kuadran CIBEST Dengan Adanya Bantuan Zakat}

\subsection{Analisis indeks kemiskinan CIBEST}

Indeks kemiskinan Islami yang terdapat dalam model CIBEST terdiri atas indeks kesejahteraan, indeks kemiskinan material, indeks kemiskinan spiritual, dan indeks kemiskinan absolut. Berdasarkan hasil analisis kuadran CIBEST, telah diketahui jumlah rumah tangga yang masuk dalam masing-masing kategori. Melalui hasil dari kuadran CIBEST tersebut maka akan didapatkan hasil dari perhitungan indeks kemiskinan Islami. Berikut adalah hasil perhitungan indeks kemiskinan Islami.

\section{Tabel 6 Indeks CIBEST Mustahik}

\begin{tabular}{cccc}
\hline Indeks CIBEST & Tanpa Zakat & Dengan Zakat & Perubahan (\%) \\
\hline W & 0.86 & 0.94 & 0.08 \\
Pm & 0.13 & 0.05 & $(0.08)$ \\
Ps & 0.00 & 0.00 & 0.00 \\
Pa & 0.01 & 0.01 & 0.00 \\
SS & 4.19 & 4.26 & 1.67 \\
\hline
\end{tabular}

Indeks kesejahteraan menggambarkan jumlah rumah tangga mustahik yang masuk dalam kategori rumah tangga sejahtera. Untuk mengetahui dampak dari pendistribusian dana zakat terhadap kesejahteraan rumah tangga mustahik maka penelitian dilakukan tanpa dan dengan adanya bantuan dana zakat. Beradasarkan Tabel 6, jumlah rumah tangga mustahik yang berada pada kategori rumah tangga sejahtera mengalami peningkatan dari 0.86 atau 86 persen menjadi 0.94 atau 94 persen. Artinya terjadi peningkatan indeks kesejahteraan rumah tangga mustahik sebesar 0.08 persen. Hasil tersebut menunjukan bahwa dengan adanya bantuan zakat terbukti dapat meningkatkan indeks kesejahteraan rumah tangga mustahik.

Indeks kemiskinan material menggambarkan jumlah rumah tangga mustahik yang masuk dalam kategori miskin secara materialnya namun kaya secara spiritual. Analisis indeks kemiskinan material terhadap rumah tangga mustahik dilakukan tanpa dan dengan adanya bantuan dana zakat yang diberikan oleh BAZNAS Provinsi Jawa Tengah. Beradasarkan dari penelitian yang sudah dilakukan, diperoleh hasil bahwa tanpa dan dengan zakat mengalami penurunan yaitu sebesar 0,08 persen. Hasil tersebut menunjukan bahwa dengan 
adanya bantuan zakat terbukti dapat menurunkan indeks kemiskinan material rumah tangga mustahik.

Indeks kemiskinan spiritual menggambarkan jumlah rumah tangga mustahik yang masuk ke dalam kategori miskin secara spiritual tetapi kaya secara material. Berdasarkan data pada Tabel 6, indeks kemiskinan spiritual rumah tangga mustahik tanpa dan dengan adanya bantuan zakat tidak mengalami perubahan.

Indeks kemiskinan absolut menggambarkan jumlah rumah tangga mustahik yang masuk ke dalam kategori miskin secara material maupun secara spiritual. Rumah tangga pada kategori ini belum mampu mencukupi kebutuhan spiritualnya maupun kebutuhan materialnya. Beradasarkan Tabel 6, indeks kemiskinan absolut tanpa dan dengan adanya bantuan zakat tidak mengalami perubahan.

Selain keempat nilai indeks yang sudah dijelaskan diatas, terdapat nilai SS atau skor ratarata kondisi spiritual keseluruhan keluarga yang diamati. Nilai SS pada tabel menunjukkan nilai sebesar 4.19 pada tanpa pendistribusian zakat dan 4.26 dengan pendistribusian zakat atau meningkat sebesar 1.67 persen. Nilai SS tersebut secara umum dapat menunjukkan bahwa keadaan spiritual keluarga yang menjadi responden sudah berada diatas garis kemiskinan spiritual tanpa dan dengan zakat. Garis kemiskinan spiritual (SV) ini besarnya yaitu sama dengan 3. . Peningkatan nilai rata-rata spiritual sangat kecil dikarenakan tidak adanya pendampingan dari BAZNAS Provinsi Jawa Tengah.

Hasil analisis indeks kemiskinan islami terhadap rumah tangga mustahik juga serupa dengan hasil penelitian yang telah dilakukan penelitian sebelumnya. Hasil tersebut menunjukkan bahwa dengan adanya bantuan zakat akan meningkatkan kesejahteraan mustahik dan menurunkan indeks kemiskinan material mustahik.

\section{Kesimpulan dan Saran}

\subsection{Kesimpulan}

Berdasarkan hasil penelitian dapat ditarik kesimpulan sebagai berikut :

1. Dengan adanya bantuan zakat, pendapatan rumah tangga mustahik mengalami peningkatan.

2. Dengan adanya bantuan zakat terjadi perubahan pada spiritual mustahik.

3. Klasifikasi rumah tangga mustahik berdasarkan Model CIBEST yang masuk kategori sejahtera (kuadran I) sebanyak 94 rumah tangga, miskin material (kuadran II) sebanyak 5 rumah tangga, miskin spiritual tidak ada, dan yang masuk kategori miskin absolut hanya 1 rumah tanggga.

4. Berdasarkan Model CIBEST menunjukkan bahwa dengan adanya bantuan zakat meningkatkan kesejahteraan mustahik dan menurunkan indeks kemiskinan material mustahik.

\subsection{Saran}

Berdasarkan hasil penelitian terkait analisis dampak zakat terhadap kemiskinan dan kesejahteraan mustahik studi kasus pada BAZNAS Provinsi Jawa Tengah, peneliti mengajukan saran sebagai berikut :

1. BAZNAS Provinsi Jawa Tengah perlu memberikan pendampingan terhadap mustahik yang menerima bantuan dana zakat. 
2. Sebaiknya pihak BAZNAS Provinsi Jawa Tengah lebih mengutamakan keluarga yang memiliki pendapatan atau pengeluarannya berada di bawah garis kemiskinan untuk menjadi mustahik. Karena dalam penelitian ini sebagian besar keluarga berada di atas garis kemiskinan Kota Semarang.

\section{Daftar Pustaka}

Beik IS. 2009. Analisis Peran Zakat dalam Mengurangi Kemiskinan: Studi Kasus Dompet Dhuafa Republika. Jurnal Pemikiran dan Gagasan. [internet]. [diunduh 2017 Februari 10] ; Vol 2.

Beik IS, Arsyianti LD. 2015. Construction of CIBEST Model as Measurement of Poverty and Welfare Indicesfrom Islamic Perspective. Al-iqtishad. [diunduh 2017 Februari 10]. Vol VII No 1

BPS. 2016. Statistik Kependudukan. Badan Pusat Statistik : Jakarta.

BPS Kota Semarang. 2015. Statistik Kependudukan. Badan Pusat Statistik : Semarang.

Hafidhuddin D, Pramulya R. 2008. Kaya Karena Berzakat. Jakarta (ID): Penebar Swadaya.

BAZNAS Provinsi Jawa Tengah. 2016. Laporan Keuangan 2016. BAZNAS Provinsi Jawa Tengah : Semarang.

Mardimin Y. 1996. Kritis Proses Pembangunan di Indonesia. Yogyakarta (ID): Kanisius.

Muslihah N. 2016. Analisis Dampak Pendistribusian Dana Zakat sebagai Pengurang Kemiskinan dengan menggunakan Model CIBEST (Kasus LAZ PM Al Bunyan Kota Bogor). [skripsi]. Bogor (ID): Institut Pertanian Bogor.

Pratama C. 2015. Pendayagunaan Zakat Produktif dalam Mengurangi Kemiskinan Beradasarkan CIBEST Model: Studi Kasus PT Masyarakat Mandiri LAZ PM Al Bunyan [skripsi]. Bogor (ID): Institut Pertanian Bogor.

Prastyo AA. 2010. Analisis Faktor-Faktor yang Mempengaruhi Tingkat Kemiskinan. UNDIPPRESS : Semarang.

Qardawi Y. 2011. Hukum Zakat. Jakarta (ID) : Litera Antarnusa.

Qonita. 2015. Analisis Zakat Sebagai Pengurang Kemiskinan: Studi Kasus Bazis Provinsi DKI Jakarta. Bogor (ID): Institut Pertannian Bogor

Tsani T. 2010. Analisis Dampak Distribusi Zakat terhadap Tingkat Kemiskinan dan Kesenjangan Pendapatan: Studi Kasus Pendayagunaan Zakat oleh BAZDA Lampung Selatan. [skripsi]. Bogor (ID): Institut Pertanian Bogor

Widyaningsih N. 2016. Studi Dampak Zakat di Sulawesi Selatan dengan Model CIBEST. Iqtishodia. [internet]. [diunduh 2017 Februari 10] 